\title{
Brain exercise in elderly: NeuroSky smarter Kit investigation
}

\author{
Tinnaphol Chaipakornwong1, Phakkharawat Sittiprapaporn² \\ ${ }^{1}$ Researcher, Brain Science and Engineering Innovation Research Group, School of Anti-Aging and Regenerative \\ Medicine, Mae Fah Luang University, Bangkok, Thailand, and Department of Anti-Aging Science, School of Anti-Aging \\ and Regenerative Medicine, Mae Fah Luang University, Bangkok, Thailand, ${ }^{2}$ Assistant Professor and Head, Brain \\ Science and Engineering Innovation Research Group, School of Anti-Aging and Regenerative Medicine, Mae Fah \\ Luang University, Bangkok, Thailand, and Department of Anti-Aging Science, School of Anti-Aging and Regenerative \\ Medicine, Mae Fah Luang University, Bangkok, Thailand
}

\section{A B S T R A C T}

Background: The measurement analysis of the brainwaves can show whether or not human's mental or cognitive status is in a sober state. The speed of the computer signal processing technology increased until it could sufficiently process the complex brainwave signals measured in real-time. Therefore, the information about the mental status thus gradually revealed a research in information science called affective computing. Aims and Objective: The purpose of this study was to study the use of NeuroSky Smarter Kit in brain exercise training program by Brainwave Cloud Classroom (BCC) system, on both attention and meditation levels' changes in elderly. Materials and Methods: The sample of this study were fifteen participants, which were four men and ten women, aged 61-84 years old. All participants were measured their attention and meditation levels by NeuroSky Smarter Kit prior to the brain training program. During the brain exercise training program by Brainwave Cloud Classroom (BCC) system, should any participant could not proceed to the next session, he/ she was measured their attention and meditation levels again. They were allowed to break for fifteen to thirty minutes or as much as they needed. Then, the second brain training was done and that participants were measured their attention and meditation levels again. Results: The result showed that attention and meditation levels were gradually increased with no statistically significant. Both theta and alpha brainwaves were increased statistically significant. Conclusion: The attention level increased while the meditation level was sustained similar to before brain exercise training. Some electroencephalographic activities including theta and alpha brainwaves were gradually increased with statistically significant while gamma brainwave did not change.

Key words: Brain Exercise; Brainwave Training; Brainwaves; Elderly People; Neurosky Smarter Kit

\section{INTRODUCTION}

Lives have prolonged and averaged age of population keeps getting higher. The elderly ratio in Thailand has tendency to continuously rising. With our knowledge, technological advancements in medical field, the widespread of public health care, faster rescue team's transportation, and the swiftness in medical diagnostic and treatment, elder people have all the chances they never have been granted before. ${ }^{1}$

Address for Correspondence:

Dr. Phakkharawat Sittiprapaporn, Assistant Professor and Head, Brain Science and Engineering Innovation Research Group, School of AntiAging and Regenerative Medicine, Mae Fah Luang University, Bangkok, Thailand. Tel No: +662 6644361. E-mail: wichian.sit@mfu.ac.th (c) Copyright AJMS 
neurologist, named Berger, starting research on human brainwaves. ${ }^{4}$ After decades of research, the results showed that measurement analysis of the brainwaves can show whether or not human's mental/cognitive status is in a sober state. ${ }^{4}$ In the recent year, the speed of the computer signal processing technology increased until it could sufficiently process the complex brainwave signals measured in real-time. Information about the mental status thus gradually revealed a research in information science called affective computing. ${ }^{3-4}$

The way we focus on specific task can cause a measurable shock to brainwaves which is recorded byelectroencephalogram (EEG). ${ }^{5}$ Previous studies reported that different forms of focus could form different brainwave frequencies which are usually recorded in the range of 1 to $50 \mathrm{~Hz}$. The integration of these neurophysiological parameters may contribute to the understanding of electroencephalographic correlates of brain training conditions. The aim of this study thus was to explore the modifications of electroencephalographic activities and Brainwave Cloud Classroom (BCC) training program in elderly. In order to detect modifications of electroencephalographic frequencies, we used the light weight electroencephalographic device, MindWave Mobile, NeuroSky, Inc. for electroencephalographic activity recordings.

\section{MATERIALS AND METHODS}

\section{Participants}

This study was done with fifteen participants, aged between 61-84 years old (mean age: 68.21 \pm 4.73 ), who were in good health, no congenital illness, no record of brain surgery, not taking medicines or drugs that affect to nervous system. Participants who had the following criteria were excluded from the study including left handedness; history of medical and neurologic diseases; binge eating disorders and other psychiatric disorders; head trauma; assumption of Central Nervous System active drugs in the two weeks prior to study entry; and presence of electroencephalographic abnormalities at the baseline recording. After receiving information about the aims of the study, all participants provided written consent to participate in the study.

\section{Tools and equipment}

Personal information of all participants including age, gender, nationality, and history of illness were recorded before starting the study. In this study, the electroencephalography (EEG) was applied in order to record the brainwaves of all participants. The effectiveness of commercially available lightweight EEG devices, NeuroSky'sMindwave Mobile, was used in this study. The neuroheadset,
NeuroSky'sMindwave Mobile, was used to display the output, analyze and record electroencephalographic activities. The principles of analytical check were based on the 10-20 system or International 10-20 system by displaying the electroencephalographic output. Mindwave Mobile provided two 100-state outputs operating at $1 \mathrm{~Hz}$ via the application of a single electrode and signal-processing unit in a headband arrangement. The principle advantage of the Mindwave Mobile was its unobtrusive nature, which minimizes the aforementioned difficulties in conducting accurate user studies. However, the Mindwave Mobile provided a much coarser picture of brain activity than multi-electrode electroencephalogram (EEG)or other technologies (Figure 1).

According to the lightweight electroencephalographic device, NeuroSky'sMindwave Mobile, theelectroencephalogram (EEG) frequency analysis was performed by means of a Fast Fourier Transform (FFT) algorithm, with a 2-second interval on the electroencephalogram (EEG)signal. The following frequency bands were considered: delta $(0.1-3.0 \mathrm{~Hz})$; theta (4.0-7.0 Hz); alpha $(8.0-13.0 \mathrm{~Hz})$; beta $(14.0-30.0 \mathrm{~Hz})$; and gamma $(31.0-60.0 \mathrm{~Hz})$. In 2009, NeuroSky released the first Brain-Computer Interfaces (BCI) control. Neurosky MindSet is different from the past BCI devices. It is a single electroencephalogram (EEG) channel comparing with the traditional multi-channels electroencephalogram (EEG) technology and makes wearing easier and more comfortable with no need of people to help you wear it. The NeuroSky product uses its patented ThinkGear chip that can filter out the noise from the EEG to get eSense. ${ }^{6}$

\section{Brain exercise training}

In brain exercise training, the Brainwave Cloud Classroom (BCC) system developed by Alchemy Technology Company, Taiwan, was used in the study. The brainwave attention lesson was divided into four different core parts. Every part had a plurality of small chapters as follows:

Part I: Meditation Practice: This part aimed to teach the brain the relaxation method by making it recognized and
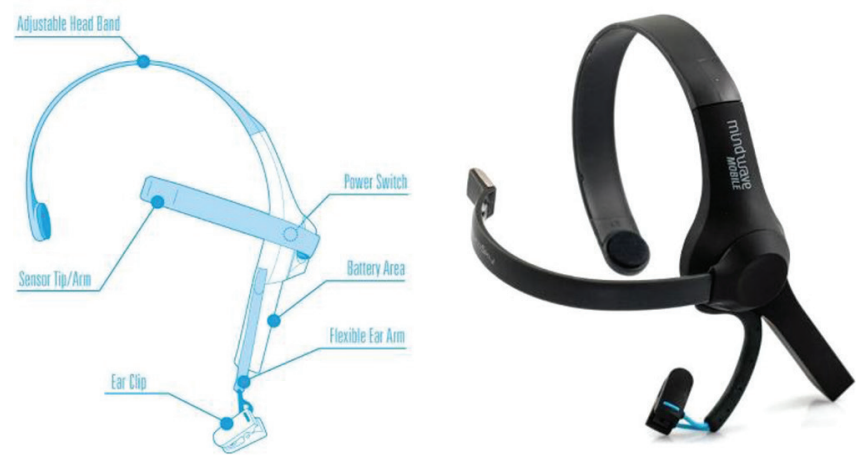

Figure 1: Mindwave mobile electroencephalography device (NeuroSky Inc.) 
remembered the state of relaxation through exercises and meditation.

Part II: Left and Right Brain Harmony: This section aimed to obtain the best results of brain development in a relaxed state by harmonizing both sides of the brain through different left and right brain exercise.

Part III: Listening, Speaking and Writing Exercises: This section aimed to train participants' listening, speaking and writing skills, so that participants could maximize while doing these things in a relaxed state. This was an important skill enhancement exercise.

Part IV: Thinking Exercise: This section aimed to train participants to be able to seriously ponder problems, and at the same time meaningfully and effectively solve them while being in a comfortable, open, and relaxed state (Figure 2).

Finally, a single-channelelectroencephalogram (EEG) was designed to collect brain activity data from the participants' brain. Simplicity and efficiency were the main reasons for designing a single-channel electroencephalographic monitoring system.

\section{Statistical analysis}

The qualitative data was summarized in term of frequency and percentage whereas the quantitative data was summarized in term of average and standard deviation. Each type of electroencephalographic activities was compared by using inferential statistic, $t$-test. Every test was set to the statistic significant at $p<0.05$.

\section{RESULTS}

In this study, the attention and mediation levels were measured both before and after brainexercise training by Brainwave Cloud Classroom (BCC) system. The attention level changed in a statistically significant at 0.05 level $(\not$-value $=0.04)$. The average before brain exercise training was $70.34( \pm 2.57)$ score and the average after brain exercise training was 80.87 ( \pm 1.51) score. For meditation level, there was no change in a statistically significant at 0.05 level $(p$-value $=0.68)$. The average before brain exercise training was $60.20( \pm 3.13)$ score and the average after brain exercise training was $60.47( \pm 3.72)$ score (Figure 3).

Based on Table 1 and Figure 4, it was found that theta and alpha brainwaves gradually increased with statistically significant at 0.05 level while delta and beta brainwaves did not change. On the other hand, gamma brainwave was found to be sustained while performing the brain exercise training program.

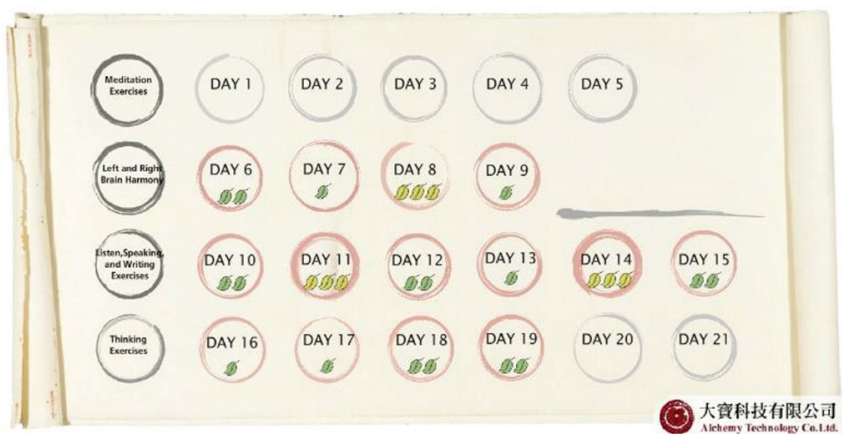

Figure 2: Brainwave Cloud Classroom (BCC) system with four major core parts

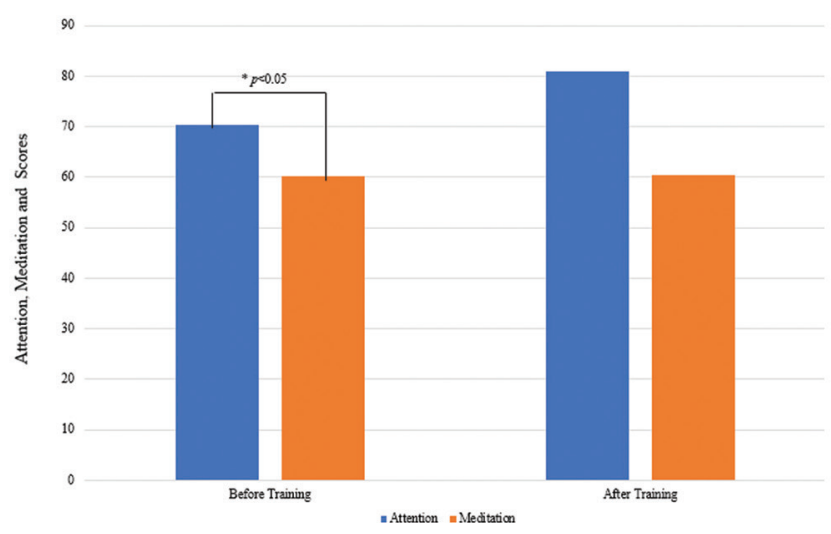

Figure 3: Attention and mediation levels were measured both before and after brain exercise training by Brainwave Cloud Classroom (BCC) system in elderly people

Delta brainwave was gradually increased with no statistically significant while having the brain exercise training program compared to baseline (before training: $0.011 \pm 0.26 \mu \mathrm{V}$; after training: $0.013 \pm 0.02 \mu \mathrm{V} ; \mathrm{t}(14)=0.18 ; p=0.41)$. Similar to delta brainwave, theta brainwave was gradually increased with statistically significant at 0.05 level while having the brain exercise training program compared to baseline (before training: $0.017 \pm 0.24 \mu \mathrm{V}$; after training: $1.14 \pm 0.71 \mu \mathrm{V} ; \mathrm{t}(14)=1.23 ; p=0.04)$. Moreover, it was found that alpha brainwave was gradually increased with statistically significant at 0.05 level while having the brain exercise training program compared to baseline(before training: $0.09 \pm 0.31 \mu \mathrm{V}$; after training: $1.03 \pm 0.03 \mu \mathrm{V}$; $\mathrm{t}(14)=0.97 ; p=0.5)$.

On the contrary, it was found that beta brainwave was gradually decreased with no statistically significant while having the brain exercise training program compared to baseline (before training: $0.008 \pm 0.006 \mu \mathrm{V}$; after training: $0.003 \pm 0.010 \mu \mathrm{V} ; \mathrm{t}(14)=1.16 ; p=0.37)$ while gamma brainwave was not changed while having the brain exercise training program compared to baseline (before training: $0.001 \pm 0.026 \mu \mathrm{V}$; after training: $0.001 \pm 0.032 \mu \mathrm{V}$; $\mathrm{t}(14)=1.12 ; p=0.29)$. 


\begin{tabular}{|c|c|c|c|c|}
\hline \multirow{2}{*}{$\begin{array}{l}\text { Electroencephalographic } \\
\text { activities }\end{array}$} & \multirow{2}{*}{$\begin{array}{c}\text { Before training } \\
\text { Mean ( } \pm S D)\end{array}$} & \multirow{2}{*}{$\begin{array}{c}\text { After training } \\
\text { Mean ( } \mathbf{S D})\end{array}$} & \multirow[t]{2}{*}{ Paired-test } & \multirow[t]{2}{*}{$p$-value } \\
\hline & & & & \\
\hline Delta brainwave & $0.011( \pm 0.26)$ & $0.013( \pm 0.02)$ & 0.18 & 0.41 \\
\hline Theta brainwave & $0.017( \pm 0.24)$ & $1.14( \pm 0.71)$ & 1.23 & $0.04^{*}$ \\
\hline Alpha brainwave & $0.09( \pm 0.31)$ & $1.03( \pm 0.03)$ & 0.97 & $0.05^{*}$ \\
\hline Beta brainwave & $0.008( \pm 0.06)$ & $0.003( \pm 0.010)$ & 0.16 & 0.37 \\
\hline Gamma brainwave & $0.001( \pm 0.026)$ & $0.001( \pm 0.032)$ & 1.12 & 0.29 \\
\hline
\end{tabular}

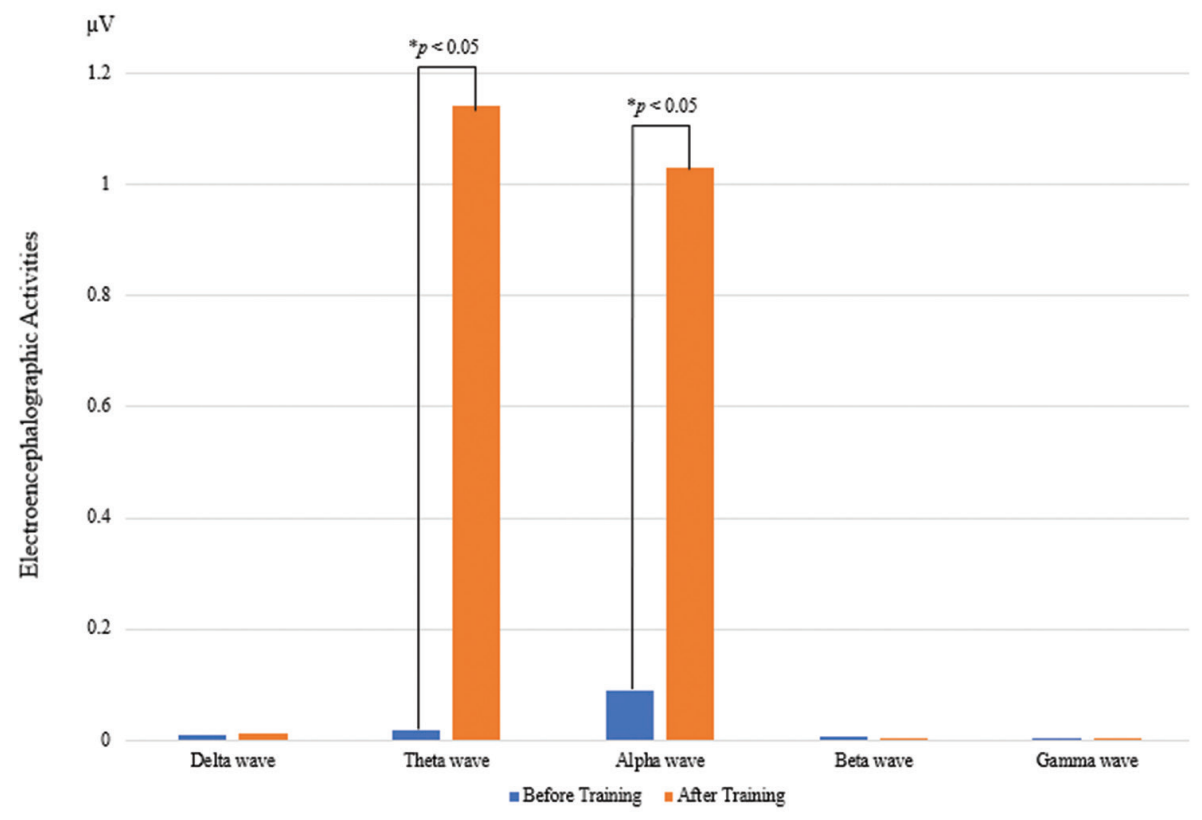

Figure 4: Comparison of brainwaves between before and after brain exercise training by Brainwave Cloud Classroom (BCC) system in elderly people

\section{DISCUSSION}

In the present study, the attention and mediation levels were measured both before and after brain exercise trainingby Brainwave Cloud Classroom (BCC) system in elderly people. The findings showed that the attention level changed in a statistically significant while the meditation level was not changed. A previous study reported that the brain training programhas been shown to be efficient in many different areas including mathematics and engineering education. ${ }^{7}$ Moreover, brain and spatial ability trainings were shown to impact capacities in scientific learning. ${ }^{8} \mathrm{~A}$ well-known of mathematics and spatial abilities training was based on the Vanderberg and Kuse $^{7}$ who developed the Mental Rotation test. After that Hoyek et al. ${ }^{9}$ used a computerized version of this Mental Rotation test to train students' spatial abilities.

As electroencephalography (EEG) is traditionally used to measure the brainwaves, each type of brainwave is associated with one's state of consciousness and different mood state..$^{10-13}$ Different neural activities will produce different brainwave patterns, thus demonstrating a different brain state. Different brainwave patterns make brainwaves of different amplitude and frequency. Beta brainwaves, which are brainwaves between 12 to $30 \mathrm{~Hz}$, mean the brain is in a focused state. Alpha brainwaves, which are brainwaves between 8 to $12 \mathrm{~Hz}$, mean the brain is in a calm, relaxed state. From all types of brainwave, beta brainwave is seen in normal activities aswell as stressful conditions or difficulties in mental concentration. On the other hand, alpha brainwaves is seen in wakefulness, relaxed, effortless and alertness condition. Therefore, persons with high alpha brainwaves and low in beta brainwaves could indicate status of relaxation, arousal, less stress and better concentration. ${ }^{14-18}$ Several investigators proposed that theta $(4-7 \mathrm{~Hz})$ brainwave activity correlated positively with the level of meditation experience. ${ }^{19}$ Some previous studies found that theta and low alpha brainwaves both increased significantly as subjects were more concentrated in the meditation task. ${ }^{20-21}$ As alpha $(8-13 \mathrm{~Hz})$ brainwave activity was known to be associated with relaxation and a lack of active cognitive processes, initial stages of meditation research focused primarily on alpha brainwave. ${ }^{20-21}$ 
The finding in the present study also revealed that theta and alpha brainwaves were gradually increased while performing the brain exercise training program of by Brainwave Cloud Classroom (BCC) system. The results of the present study were consistent with previous studies showing that the sensorimotor rhythm related to attention. ${ }^{18,22}$ In addition, the increase of both theta and alpha brainwaves in the present study was consistent with previous studies mentioning the increase of theta and alpha powers indicated in the frontal areas. ${ }^{23-24}$ In addition, previous studies had shown that both theta and alpha oscillations were known to play an important role in different memory processes and in emotion regulation. ${ }^{24-25}$ However, other studies have indicated that theta and alpha brainwaves responded specifically to visual emotional stimulation and to negative emotions, respectively. ${ }^{26}$

\section{CONCLUSION}

This study aimed to study the attention and meditation levels as well as electroencephalographic activities changes during the brain exercise training program of by Brainwave Cloud Classroom (BCC) systemin elderly. While performing the brain exercise training program by Brainwave Cloud Classroom (BCC) system, the attention and meditation as well as electroencephalographic activities were recorded by using the lightweight electroencephalographic device, Mindwave Mobile, NeuroSky, Inc. The attention level increased while the meditation level was sustained similar to before brain exercise trainingby Brainwave Cloud Classroom (BCC) system. Some electroencephalographic activities including theta and alpha brainwaves were gradually increased with statistically significant while gamma brainwave did not change.

\section{ACKNOWLEDGEMENT}

This research was supported by research funding from Mae Fah Luang University grant (Electroencephalogram Laboratory 2019), Brain Science and Engineering Innovation Research Group, Mae Fah Luang University grant 2019 (MFU-grant no. 611U109005) and 2020, Thailand. We thank all of the subjects involved in this research as main data provider of this studies.

\section{REFERENCES}

1. Yaiyong $O$ and Lueboonthavatchai P.Depression and Grief of the Elderly at the Elderly Associate in Nonthaburi Province, $\mathrm{J}$ Psychiatr Assoc Thailand 2011;56(2): 117-128.

2. Bailey SP, Hall EE, Folger A and Miller PC. Changes in EEG during graded exercise on a recumbent cycle ergometer.
J Sports Sci Med 2008; 7: 505-511.

3. Popper KR and Eccles JC. The self and its brain: an argument for interactionism1977, Berlin: Springer-Verlag Berlin Heidelberg.

4. Bergerz $\mathrm{H}$, Uber das Elektroenkephalogram des Menschen, In: AfPN, 1929; 87: 527-570. Berlin: Springer.

5. Crowley K, Sliney A, Pitt I and Murphy D. Evaluating a Brain-Computer Interface to Categorize Human Emotional Response. IEEE $10^{\text {th }}$ International Conference on Advanced Learning Technologies (ICALT) 2010, pp. 276-278, Sousse: IEEE Press.

6. NeuroSky, Inc.NeuroSky'seSense ${ }^{\mathrm{TM}}$ meters and detection of mental state. Technical Report, 2009. NeuroSky, Inc.

7. Hoyek N, Collet C, Rastello O, Fargier P, Thiriet $P$ and Guillot A. Enhancement of mental rotation abilities and its effect on anatomy learning. Teaching and Learning Med 2009; 21:201-206.

8. Vromen A, Verbunt JA, Rasquin S and Wade DT. Motor imagery in patients with a right hemisphere stroke and unilateral neglect. Brain Injury 2011; 25:387-393.

9. Bishop AJ. Spatial abilities and mathematics education - a review. Edu. Studies Math 1980; 11: 257-269.

10. Allen JJB, Coan JA and Nazarian M. Issues and assumptions on the road from raw signals to metrics of frontal EEG asymmetry in emotion. Biol Psychol 2004; 67: 183-218.

11. Crabbe JB and Dishman RK. Brain electrocortical activity during and after exercise: A quantitive synthesis. Psychophysiol 2004; 41: 563-574.

12. Davis JM and Bailey SP. Possible mechanisms of central nervous system fatigue during exercise. Med Sci Sport Exer1997; 29(1): 45-57.

13. Kakizaki T. Effects of bicycle exercise on occipital EEG amplitude in male students. Industrial Health 1988; 26: 191-195.

14. Black WR, Lepping RJ, Bruce AS, Powell JN, Bruce JM and Martin LE. Tonic hyper-connectivity of reward neurocircuitry in obese children. Obesity (Silver Spring)2014; 22(7): 1590-1593.

15. Garcia-Garcia I, Jurado MA, Garolera M, Segura B, MarquesIturria I and Pueyo R. Functional connectivity in obesity during reward processing. Neurolmage 2012; 66C: 232-239.

16. Tregellas JR, Wylie KP, Rojas DC, Tanabe J, Martin JK and Kronberg E. Altered default network activity in obesity. Obesity (Silver Spring) 2011; 19(12): 2316-2321.

17. Tammela LI, Paakkonen A, Karhunen LJ, Karhu J, Uusitupa MI and Kukka JT. Brain electrical activity during food presentation in obese binge-eating women. Clin Physiol Funct Imaging 2010; 30(2): 135-140.

18. Ford MR, Goethe JW and Dekker DK. EEG coherence and power in the discrimination of psychiatric disorders and medication effects. Biol Psychiatry 1986; 21(12): 1175-1188.

19. Lagopoulos J, Xu J, Rasmussen I, Vik A, Malhi GS and Eliassen CF. Increased Theta and Alpha EEG Activity During Nondirective Meditation. J Altern Complement Med 2009;15(11):1187-1192.

20. Pfurtscheller G, Jr. Stancak A and Neuper C. Event-related Synchronization (ERS) in the Alpha Band-an Electrophysiological Correlate of Cortical Idling: A Review. Int J Psychophysiol 1996; 24:39-46.

21. Jensen $O$ and Mazaheri A. Shaping Functional Architecture by Oscillatory Alpha Activity: Gating by Inhibition. Front Hum Neurosci 2010;4:186.

22. Balconi M. Frontal brain oscillation modulation in facial emotion comprehension. The role of reward and inhibitory systems in subliminal and supraliminal processing. Eur $\mathrm{J}$ Cog Psychol 2011; 23(6): 723-735. 
23. Klimesch W, Sauseng $P$ and Hanslmayr S. EEG alpha oscillations: the inhibition-timing hypothesis. Brain Res Rev 2007; 53(1): 63-88.

24. Crews FT and Boettiger CA. Impulsivity, frontal lobes and risk for addiction. Pharmacol Biochem Behav 2009; 93(3): 237-247.

25. Parvaz MA, Alia-Klein N, Woicik PA, Volkow ND and
Goldstein RZ. Neuroimaging for drug addiction and related behaviors. Rev Neurosci 2011; 22(6): 609-624.

26. Jensen O, Gelfand J, Kounios J and Lisman JE. Oscillations in the alpha band $(9-12 \mathrm{~Hz})$ increase with memory load during retention in a short-term memory task. Cereb Cort 2002; 12(8): 877-882.

\section{Authors Contribution:}

TC- Concept and design of the study, statistically analyzed and interpreted; PS- Concept and design of the study, statistically analyzed and interpreted manuscript preparation, critical revision of the manuscript.

\section{Work attributed to:}

Brain Science and Engineering Innovation Research Group

School of Anti-Aging and Regenerative Medicine, Mae Fah Luang University, Thailand

\section{Orcid ID:}

Mr. TinnapholChaipakornwongg - (10) https://orcid.org/0000-0002-4550-649X

Dr. Phakkharawat Sittiprapaporn - (i) https://orcid.org/0000-0002-4103-9396

Source of Support: Mae Fah Luang University grant (Electroencephalogram Laboratory 2019), Thailand; Brain Science and Engineering Innovation Research Group, Mae Fah Luang University grant 2019 (MFU-grant no. 611U109005) and 2020, Thailand. Conflict of Interest: None declared. 